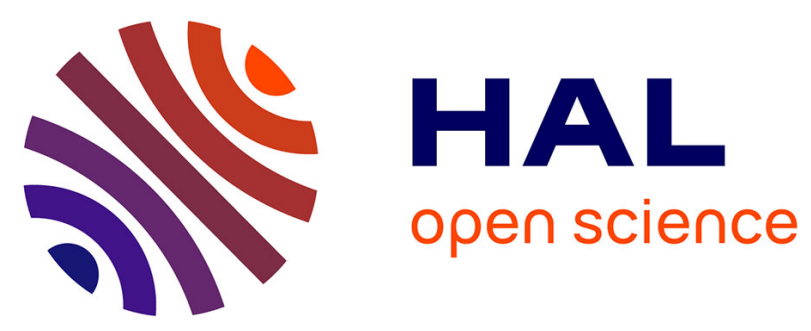

\title{
Respiration activity monitoring system (RAMOS), an efficient tool to study the influence of the oxygen transfer rate on the synthesis of lipopeptide by Bacillus subtilis ATCC6633
}

\author{
Jean-Sebastien Guez, C H Müller, P M Danze, J Büchs, P Jacques
}

\section{To cite this version:}

Jean-Sebastien Guez, C H Müller, P M Danze, J Büchs, P Jacques. Respiration activity monitoring system (RAMOS), an efficient tool to study the influence of the oxygen transfer rate on the synthesis of lipopeptide by Bacillus subtilis ATCC6633. Journal of Biotechnology, 2008, 134 (1-2), pp.121-126. 10.1016/j.jbiotec.2008.01.003 . hal-02939005

\section{HAL Id: hal-02939005 https://hal.science/hal-02939005}

Submitted on 17 Sep 2020

HAL is a multi-disciplinary open access archive for the deposit and dissemination of scientific research documents, whether they are published or not. The documents may come from teaching and research institutions in France or abroad, or from public or private research centers.
L'archive ouverte pluridisciplinaire HAL, est destinée au dépôt et à la diffusion de documents scientifiques de niveau recherche, publiés ou non, émanant des établissements d'enseignement et de recherche français ou étrangers, des laboratoires publics ou privés. 
Respiration Activity MOnitoring System (RAMOS), an efficient tool to study the influence of the oxygen transfer rate on the synthesis of lipopeptide by Bacillus subtilis ATCC6633

\section{J.S. GUEZ ${ }^{\mathrm{a}}$, C.H. MÜLLER ${ }^{\mathrm{b}}$, P.M. DANZE ${ }^{\mathrm{c}}$, J. BÜCHS $^{\mathrm{b}}$, P. JACQUES ${ }^{\mathrm{a}}$}

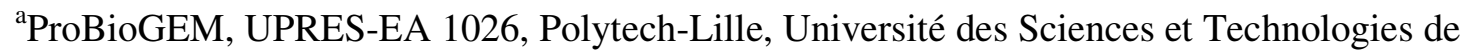
Lille, Bd Paul Langevin, 59655 Villeneuve d'Ascq, France

${ }^{\mathrm{b}}$ Biochemical engineering, RWTH Aachen University, Sammelbau Biologie, Worringerweg 1, 52074 Aachen, Germany

${ }^{\mathrm{c} I F R} 114-I M P R T$ (functional genomic platform), Faculté de Médecine H. Warembourg, Place de Verdun, F-59045 Lille

(*) Author for correspondence: jean-sebastien.guez@ polytech-lille.fr

Tel : 0033 (0)32876 7409

Fax : $0033(0) 328767401$

Keywords: RAMOS, oxygen transfer rate, biosurfactant lipopeptide, mycosubtilin, Bacillus subtilis, transcript analysis 


\begin{abstract}
The effect of oxygen transfer rate on the synthesis of mycosubtilin, a non ribosomal lipopeptide antifungal biosurfactant, was investigated in the Respiration Activity MOnitoring System (RAMOS) for two Bacillus subtilis strains. These cultures were performed under definite oxygen-limited conditions without the adding of any anti-foam in the culture medium. By using four different filling volumes in the shaken bioreactors, different levels $(20,14,9$ and $7 \mathrm{mmol} \mathrm{O} \mathrm{O}_{2} \mathrm{l}^{-1} \cdot \mathrm{h}^{-1}$ ) of oxygen-limited growth could be obtained. A 25 -fold increase of the specific productivity of mycosubtilin was observed for Bacillus subtilis ATCC6633 in the case of the most severe oxygen limitation. But nearly no effect could be found with strain BBG100 carrying the constitutive $\mathrm{P}_{r e p U}$ promoter instead of the natural $\mathrm{P}_{m y c}$ promoter. Transcript analysis of the fenF gene belonging to the myc operon indicated that the $\mathrm{P}_{m y c}$ promoter regulation could be slightly oxygen sensitive. Additionally, different patterns of the synthetised mycosubtilin homologues were obtained for different level of oxygen-limited growths. At the present state of investigation, oxygen regulation was thus shown to act at different levels suggesting the existence of a complex regulatory system of NRPS lipopeptide synthesis in the natural B. subtilis ATCC6633 strain.
\end{abstract}




\section{Introduction}

Bacillus subtilis is known for its ability to produce several bioactive nonribosomal peptides (Grünewald and Marahiel, 2006) and among others, lipopeptides which are classified into three main families according to their chemical structure: surfactins, fengycins and iturins (Bonmatin et al., 2003, Schneider et al., 1999). The family of iturins composed of iturin A, $A_{L}$ C, mycosubtillin, bacillomycin F, L, D, and LC. Most of them combine biosurfactant and antifungal activities. In particular, mycosubtilin which is a pore-forming lipopeptide (MagetDanat and Peypoux, 1994) is considered as one of the most antifungal iturinic compounds. The first strain Bacillus subtilis ATCC6633 used in this work is a natural mycosubtilin and surfactin producer (Duitman et al., 1999). The second strain, BBG100, is a mycosubtilin overproducing derivative (Leclère et al., 2005).

The production process of lipopeptide is known to be influenced by environmental conditions such as $\mathrm{pH}$, temperature, agitation and oxygen availability (Desai and Banat, 1997). In particular, oxygen availability changes metabolic pathways and fluxes in Bacilli (Çalik et al., 2000) affecting the synthesis of lipopeptide (Ohno et al., 1993, Jacques et al., 1999). Most of the studies investigating this effect were carried out in shake flasks with conventional agitation, filling volumes or plugs changing methods but no data on oxygen transfer rate (OTR) are available. In stirred bioreactors, only few references report the effect of the culture parameters on the production of non ribosomal lipopeptides, namely surfactin (Sen and Swaminathan, 1997) and surfactin/iturin A (Hbid et al., 1996). In the first article, the authors showed that a low agitation and high aeration rate favoured the synthesis of surfactin by strain B. subtilis DSM 3256. In the second article, the authors showed that, when the stirring rate decreases, B. subtilis $\mathrm{S} 499$ produces half as much surfactin and twice as much iturin. These latter experiments were performed in the presence of oxygen vectors that may have influenced the cell metabolism. No clear evidence of the effect of the OTR could be drawn from these 
studies because of the absence of gas analysis and of the influence of the oxygen transfer conditions on the foaming. The lack of studies on this topic principally arise from the difficulty to manage the high foaming capacity of the culture medium during the production process in bioreactors, especially as the adding of synthetic or natural antifoam is not recommended because of the risk of interferences with the physiological state of the strain (Lee and Kim, 2004).

For the first time, our work investigates the effect of oxygen limitation on the lipopeptide biosurfactant synthesis under definite OTR conditions. The OTR was measured online using the Respiration Activity MOnitoring System (RAMOS) described previously (Anderlei et al., 2004). In our study, there was no need to add antifoam in the culture medium since the surface aeration strategy in shaken reactors decreased the broth foaming capacity. The effect of oxygen on the natural $\mathrm{P}_{m y c}$ promoter of the myc operon encoding for the mycosubtilin synthetase was discussed. Indirect influence of OTR was pointed out with showing the different mycosubtilin homologues patterns obtained for the different oxygen-limited growths.

\section{Materials and Methods}

\section{Strains and growth conditions}

B. subtilis ATCC6633, a mycosubtilin and surfactin producer, and the derivative BBG100 were tested in this study. BBG100 was previously obtained in our laboratory by replacing the native promoter $\mathrm{P}_{m y c}$ of the mycosubtilin synthetase operon by a constitutive promoter $\mathrm{P}_{r e p U}$ originating from Staphylococcus aureus plasmid pUB110. The preculture medium (Clark, 1981) was inoculated with a loopful of cells conserved at $-80^{\circ} \mathrm{C}$. Cells were grown in Erlenmeyer flasks at $30^{\circ} \mathrm{C}$ with a shaking speed of $140 \mathrm{rpm}$. Cells were then alternatively 
transferred to RAMOS flasks or Erlenmeyer flasks containing the modified Landy medium pH 7.0 composed as follows : Glucose, 20 g. $1^{-1}$; $\left(\mathrm{NH}_{4}\right)_{2} \mathrm{SO}_{4}, 2.3$ g. $1^{-1}$, Glutamic acid, 2 g. $1^{-1}$; $\mathrm{K}_{2} \mathrm{HPO}_{4}, 1$ g.l ${ }^{-1} ; \mathrm{MgSO}_{4} 0.5$ g..$^{-1} ; \mathrm{KCl}, 0.5$ g.l ${ }^{-1} ; \mathrm{CuSO}_{4}, 1.6 \mathrm{mg} .1^{-1} ; \mathrm{Fe}_{2}\left(\mathrm{SO}_{4}\right)_{3}, 1.2 \mathrm{mg} .1^{-1}$; $\mathrm{MnSO}_{4}, \quad 0.4 \quad \mathrm{mg} . \mathrm{l}^{-1}$. Culture medium was buffered with MOPS (3-(Nmorpholino)propanesulfonic acid) $100 \mathrm{mM}$ and no yeast extract was added. Before inoculation, the preculture was centrifuged and washed in 9 g. $1^{-1} \mathrm{NaCl}$ solution. The starting optical density of the main culture was 0.25 corresponding to a biomass concentration of 0.8 $\mathrm{g}(\mathrm{D} . \mathrm{W}) \cdot \mathrm{I}^{-1}$. The optical density was measured at $600 \mathrm{~nm}$ using a Kontron Uvicon 922. The cultures led in Erlenmeyer flasks were realised in triplicate.

\section{RAMOS system}

The OTR was measured online using the RAMOS (Anderlei et al., 2004). By using four different filling volumes (FV) of $10 \mathrm{ml}, 25 \mathrm{ml}, 42 \mathrm{ml}$ and $60 \mathrm{ml}$ corresponding to filling volume ratios (FVR) of $0.04,0.1,0.17$ and 0.24 , four levels of oxygen transfer capacity could be obtained in $250 \mathrm{ml}$ RAMOS flasks for strain ATCC6633. Three non-monitored shake flasks were cultivated simultaneously under same conditions and used for sampling. Each sample flask was only used once in order to avoid the modification of the flask filling volume. The shaker was operated at $175 \mathrm{rpm}, 50 \mathrm{~mm}$ shaking diameter and the temperature set at $30^{\circ} \mathrm{C}$. Similar experiments were conducted with strain BBG100 by using 10, 42 and $60 \mathrm{ml}$ filling volumes.

\section{Analysis}

Culture samples were centrifuged at $10,000 \mathrm{~g}$ for $10 \mathrm{~min}$. A volume of $1 \mathrm{ml}$ of the supernatants was purified through C18 Maxi-Clean cartridges (Alltech) following the protocol described previously (Guez et al., 2007) ${ }^{\mathrm{a}}$ for lipopeptide HPLC analysis. Purified mycosubtilins and surfactins used as standards were supplied by Sigma. The retention time and second derivative of the absorption spectrum between 200 and $400 \mathrm{~nm}$ (Diode Array 
PDA 996, Waters) were used to identify the eluted molecules (Millenium Software, Waters). Determination of the retention time of the major C-16 and C-17 mycosubtilin homologues was done with injecting purified fractions in HPLC $\left(\mathrm{Guez}, 2007^{\mathrm{b}}\right)$. The identification of these homologues was done with performing MALDI-MS analysis (Brucker Ultraflex tof, Brucker Daltonics) as described previously (Leclère et al., 2005).

Glucose concentrations were determined using a Dionex HPLC system with an organic-acidresin column $(300 \times 8 \mathrm{~mm}, \mathrm{CS}-\mathrm{Chromatography})$ at $60^{\circ} \mathrm{C}$. Samples were prefiltered on 0.45 $\mu \mathrm{m}$ Millex-HV (Millipore). Sulphuric acid $1 \mathrm{mM}$ mobile phase was pumped at a flow rate of $0.8 \mathrm{ml} \cdot \mathrm{min}^{-1}$.

Enzymatic assay was used to analyse the L-glutamic acid (Enzytec Fluid, Scil Diagnostic, Germany).

\section{RNA isolation and reverse transcription}

Culture samples were taken after two doubling times $(n=2)$ which corresponded to the early exponential growth and four doubling times $(n=4)$ which corresponded to the beginning of the oxygen-limited growth. Data corresponding to $n=2$ and $n=4$ originates from two independent duplicate sets in order to avoid the modification of the flasks filling volume. A volume corresponding to $1.10^{9}$ cells was sampled and added to the Ambion Ribopure RNALater solution (v/v), mixed thoroughly during $10 \mathrm{~s}$ and centrifuged $10 \mathrm{~min}$ at $-9^{\circ} \mathrm{C}$ and $11000 \mathrm{~g}$. The supernatant was discarded and the pellet stored at $-80^{\circ} \mathrm{C}$.

Authors recently mentioned that a natural isolate like ATCC6633 was difficult to transform (Duitman et al., 2007). In the frame of this work, it should be added that RNA isolation of ATCC6633 is also difficult to perform with respect to the high resistance of its cell wall. For isolation of RNA, the cell pellets were resuspended in $50 \mu \mathrm{l}$ of a $10 \mathrm{mg} \cdot \mathrm{ml}^{-1}$ lysosyme solution. After $10 \mathrm{~min}$ of incubation at $37^{\circ} \mathrm{C}, 350 \mu \mathrm{l}$ of RNAWiz phenolic solution were added. Mechanical cell lysis in the presence of $250 \mu \mathrm{l}$ of zirconium beads was led for $10 \mathrm{~min}$ 
at maximal speed (Mixer Mill 200). The lysate was then centriguged $5 \mathrm{~min}$ at $12000 \mathrm{~g}$ and $4^{\circ} \mathrm{C}$. After having discarded the beads, 0.2 volume of chloroform was added. The mixture was incubated $10 \mathrm{~min}$ at room temperature and centrifuged $5 \mathrm{~min}$ at $12000 \mathrm{~g}$ and $4^{\circ} \mathrm{C}$. The aqueous phase was retrieved and 0.5 volume of ethanol added. Purification of RNA was then completed following the Ribopure Ambion protocole. The quantity of total RNAs was measured with a Nanodrop ND-1000 spectrophotometer. The quality was estimated with calculating the RNA 23S/16S ratio with a capillary electrophoresis (RNA 6000 NanoAssay, Agilent 2100 bioanalyzer).

The reverse-transcription was done with mixing $3 \mu \mathrm{g}$ of total RNA and $0.5 \mu \mathrm{l}$ hexamers (Invitrogen) to a final volume of $8.2 \mu \mathrm{l}$ in $\mathrm{H}_{2} \mathrm{O}$. The mixture was heated at $65^{\circ} \mathrm{C}$ for $10 \mathrm{~min}$ and cooled at $4^{\circ} \mathrm{C}$ before the adding of $3 \mu \mathrm{l}$ of 5X First Strand Buffer (Invitrogen), $1.5 \mu \mathrm{l}$ of 0.1M DTT (Invitrogen), $0.3 \mu \mathrm{l}$ of $25 \mathrm{mM}$ dATP, dGTP, dCTP, dTTP (Amersham), $1 \mu \mathrm{l}$ of Rnase Inhibitor and $1 \mu 1$ of SuperScript II (200 U/ $\mu 1$, Invitrogen). Incubation of this mixture at $42^{\circ} \mathrm{C}$ during $1 \mathrm{~h}$ was followed by the adding of $0.5 \mu \mathrm{l}$ SuperScript II and a subsequent incubation at $42^{\circ} \mathrm{C}$ during $45 \mathrm{~min}$. To estimate the level of expression of the myc gene coding for the mycosubtilin synthetase, a $398 \mathrm{bp}$ PCR product belonging to the fenF locus of the myc operon was amplified using the following pair of oligonucleotides : 5'CAAAATGCAGATCCTGAGCA-3' and 5'-GGCATAGTCATGTGCGTTTG-3'. PCR products were analysed by electrophoresis on $1.5 \%$ agarose gel and the Median-based Trimmed Mean density (MTM) values of the bands were obtained thanks to Arrayvision scanner (Qiagen). MTM values of each band corresponding to fenF products were normalised with the MTM values of a $330 \mathrm{bp}$ amplified product belonging to $r p l L$, a housekeeping gene of $B$. subtilis coding for the ribosomal protein L12. Results were rescaled with respect to the experiment led at FVR=0.05. The following pair of oligonucleotides 5'GCTTCCGTTAAAGAAGCAACTG-3' and '5'-AGAAGCGCCAACTTCTTCAA-3' were 
used for $r p l L$. The PCR mixture was done with the following reagents: cDNA, $0.5 \mu \mathrm{L} ; 10 \mathrm{X}$ buffer, $2,5 \mu \mathrm{l}$; dNTP $(2.5 \mathrm{mM}), 1 \mu \mathrm{l} ; \mathrm{MgCl}_{2}(25 \mathrm{mM}), 1.5 \mu \mathrm{l}$; forward primer, $0.5 \mu \mathrm{L}$; reverse primer, $0.5 \mu \mathrm{L}$, completed to $25 \mu \mathrm{l}$ with $\mathrm{H}_{2} \mathrm{O} .0 .2 \mu \mathrm{l}$ of Taq Gold $(5 \mathrm{U} / \mu \mathrm{l})$ are then added to the mixture. The amplification conditions were $5 \mathrm{~min}$ at $94^{\circ} \mathrm{C}$ followed by 30 cycles: $30 \mathrm{~s}$ at $94^{\circ} \mathrm{C}, 30 \mathrm{~s}$ at $56^{\circ} \mathrm{C}, 60 \mathrm{~s}$ at $72^{\circ} \mathrm{C}$ and one cycle at $72^{\circ} \mathrm{C}$ for $5 \mathrm{~min}$ before conservation of the PCR product at $4^{\circ} \mathrm{C}$.

\section{Results}

OTR-monitored cultures of ATCC6633 were first led in RAMOS flasks. Figure 1 shows the oxygen transfer rate (OTR) evolution. After a period of latency of $10 \mathrm{~h}$ due to the absence of yeast extract in the culture medium, the oxygen transfer rate increased until the maximal oxygen transfer rate was reached. RAMOS flasks with filling volumes of 60, 42, 25 and $10 \mathrm{ml}$ allowed oxygen-limited growths at 7, 9, 14 and $20 \mathrm{mmol} \mathrm{O}_{2} \cdot \mathrm{L}^{-1} \cdot \mathrm{h}^{-1}$ respectively. A decrease in the OTR then occurred successively for the experiments at a FV of 10, 25 and $42 \mathrm{ml}$ because of the complete consumption of the carbon source. In case of the most severe oxygenlimitation obtained at a FV of $60 \mathrm{ml}$, the experiment was ended before total depletion of the carbon source. HPLC analysis showed that $0.45 \mathrm{~g} . \mathrm{l}^{-1}$ of glucose and $0.056 \mathrm{~g} . \mathrm{l}^{-1}$ of glutamic acid remained in the culture medium at $48 \mathrm{~h}$ (table 1). B. subtilis ATCC6633 and BBG100 showed similar $\mathrm{pH}$ evolution for the different oxygen-limited growths. The $\mathrm{pH}$ dropped from 7.0+/-0.04 to respectively $6.06+/-0.03$ and 5.98+/-0.11 after 48 hours of culture (Table 1).

Oxygen availability played an important role in the lipopeptide synthesis by ATCC6633. The mycosubtilin production increased with the strength of the oxygen limitation from 2.4 to 45.4 mg. $1^{-1}$ (figure $2 \mathrm{~A}$ ). This result was amplified for the mycosubtilin specific productivity as the increase ranged from 0.001 to $0.025 \mathrm{mg} \cdot \mathrm{g}(\mathrm{DW})^{-1} \mathrm{~h}^{-1}$ (table 1$)$. In the case of the BBG100 strain carrying the constitutive $\mathrm{P}_{r e p U}$ promoter instead of the native $\mathrm{P}_{m y c}$, the mycosubtilin production remained quite constant in the range of 70 to $80 \mathrm{mg} . \mathrm{l}^{-1}$ (figure 2B) and the specific 
productivity in the range of 0.033 to $0.035 \mathrm{mg} \cdot \mathrm{g}(\mathrm{DW})^{-1} \cdot \mathrm{h}^{-1}$ (table 1 ). Considering the experiments where the carbon sources were totally depleted before the end of the culture, no diminution of the mycosubtilin production was observed during the culture (fig $2 \mathrm{~A}$ ) whereas this phenomenon occurred in the case of surfactin (figure $2 \mathrm{C}$ ) rending the surfactin production kinetics difficult to analyse. Nevertheless, the surfactin production by the mycosubtilin overproducing strain BBG100 (figure 2D) was reduced in comparison to ATCC6633.

Oxygen dependent regulation of the native $\mathrm{P}_{m y c}$ promoter of ATCC6633 was inspected through a transcript analysis performed on the fen $F$ gene that belongs to the myc operon coding for the mycosubtilin synthetase. Figure 3 shows comparative RT-PCR results obtained for different oxygen-limited growths led in $500 \mathrm{ml}$ non-monitored Erlenmeyer flasks filled with 20,50, 100 and $200 \mathrm{ml}$ corresponding to FVR of 0.05, 0.1, 0.2, and 0.4. At $\mathrm{n}=2$, MTM ratios of fenF were quite similar for the different FVR indicating the absence of transcriptional regulation of the $\mathrm{P}_{m y c}$ promoter in the early exponential growth, i.e before oxygen-limited growth. At $n=4$ and a FVR ranging from 0.05 to 0.2 , the expression of $f e n F$ slightly increased whereas the mycosubtilin specific productivity was also shown to increase from 0.002 to $0.029 \mathrm{mg} \cdot \mathrm{g}(\mathrm{DW})^{-1} \cdot \mathrm{h}^{-1}$ (figure 4). Compared to $\mathrm{FVR}=0.1$ or $\mathrm{FVR}=0.2$, the fenF expression then decreased at $\mathrm{FVR}=0.4$. In this experiment, the mycosubtilin specific productivity interestingly dropped to $0.014 \mathrm{mg} \cdot \mathrm{g}(\mathrm{DW})^{-1} \cdot \mathrm{h}^{-1}$. This result showed that the positive effect of oxygen-limited growth on the mycosubtilin synthesis can be inverted in the case of too severe oxygen limitations.

Different mycosubtilin homologues patterns were obtained for the different oxygen-limited growths in Erlenmeyer flasks at a FVR of $0.05,0.1,0.2$ and 0.4 (figure 4). Patterns corresponding to FVR of 0.2 and 0.4 showed a quite constant distribution of the mycosubtilin C-16 and C-17 homologues. Patterns corresponding to FVR of 0.05 or 0.1 showed an increase of the C-16 mycosubtilin and a slight decrease of the C-17 mycosubtilin. The high standard 
deviations determined for the FVR=0.05 sample result from the low level of mycosubtilin produced in these conditions.

\section{Discussion}

Among the environmental factors affecting the production of lipopeptide biosurfactants, authors pointed out the importance of the $\mathrm{pH}$ for microorganism in general (Desai et al., 1997) and B. subtilis ATCC6633 in particular $(\text { Guez, 2007) })^{\mathrm{b}}$. Effects of the $\mathrm{pH}$ were therefore largely reduced in this study with buffering the medium with MOPS $100 \mathrm{mM}$.

Combined results obtained in RAMOS and Erlenmeyer flasks showed that the gain in mycosubtilin productivity could be lost in the case of too severe oxygen limitations. Indeed, an increase of the rate of mycosubtilin synthesis was observed when the strength of definite oxygen limitation increased from 0.04 to 0.24 . Further experiments led in non-monitored flasks between FVR of 0.05 and 0.2 confirmed this result. These latter experiments allowed the testing of a higher FVR of 0.4 which led to a dramatic drop in the lipopeptide synthesis.

Considering the oxygen positive effect, a 25 -fold increase of the mycosubtilin productivity was observed at a FVR of 0.24 compared to a FVR of 0.04 . Authors previously observed an increase of the iturin A production rate as the stirring decreased in the bioreactor, i.e. as the oxygen transfer was decreased (Hbid et al., 1996). It is known that iturinA and mycosubtilin have almost the same structure while the amino acids at positions 6 and 7, D-Ser $\rightarrow$ L-Asn, are inverted in iturin A. Consequently, the positive oxygen regulation observed for the mycosubtilin synthesis in ATCC6633 could be found in the iturin A producing strain, $B$. subtilis S499.

In oxygen-monitored flasks, no effect of oxygen could be found for the BBG100 strain carrying the constitutive $\mathrm{P}_{r e p U}$ promoter instead of the native $\mathrm{P}_{m y c}$. It was suggested that oxygen metabolism could interfere in the regulation of the native $\mathrm{P}_{m y c}$ promoter. At the 
beginning of the oxygen-limited growths of ATCC6633, a constant expression of fenF was found at FVR of $0.05,0.1$ and 0.2. Interestingly, an increase of the expression of fenF was observed at a FVR of $0.1-0.2$ compared to a FVR of 0.05 with respect to the increasing mycosubtilin specific productivity. Furthermore, a slight decrease of $f e n F$ expression was observed at FVR of 0.4 with respect to the low value of the mycosubtilin synthesis. It was recently demonstrated by pulse-chase experiments that the incorporation of C-10 to C-16 fatty acid moieties in mycosubtilin by the acyl ligase domain of the mycosubtilin synthetase was not specific (Hansen et al., 2007). These results suggested that the intracellular pool of fatty acid homologues could modulate the synthesis of mycosubtilin homologues. In our experiments, the different mycosubtilin homologues patterns obtained for the different oxygen-limited growths could express an indirect influence of OTR on the fatty acid synthesis and thus on the lipopeptide synthesis.

It was also shown in RAMOS experiments that surfactin production by the mycosubtilin overproducing strain BBG100 was lowered in comparison to ATCC6633. A study showed that the expression of both lipopeptides was clearly not coordinated as the srfA operon was mainly regulated by the response regulator ComA and the myc operon was primarily regulated by the transition state regulator AbrB (Duitman et al., 2007). However mycosubtilin and surfactin synthetases require an identical cofactor, the 4'-phosphopantetheinate, which transfer is catalysed by the product of the gene $s f p$ which encode a 4'-phosphopantetheinyl transferase. This activation step could be limiting for surfactin synthetase when mycosubtilin synthetase is overproduced.

To end with, the diminution of surfactin concentration observed during the RAMOS culture at a FV of 10, 25 and $42 \mathrm{ml}$ is not yet explained. It could result from a re-use of the surfactin as a substrate by the strain since it appeared only in culture where carbon source depletion was previously observed. 


\section{Conclusion}

This study showed that definite oxygen metabolism effectively modulates the synthesis of a NRPS lipopeptide in B. subtilis ATCC6633. For the first time, the difficulty of monitoring the bacteria respiration during the production process of a biosurfactant was overcome. It highlights in particular the high potential of RAMOS system for physiological studies on biosurfactant synthesis. Providing knowledge of the effect of OTR on mycosubtilin synthesis by B. subtilis ATCC6633 allowed equalising the specific productivity obtained by a genetically modified derivative of ATCC6633 by simply manipulating an external parameter as OTR.

\section{Acknowledgements}

This work received the financial support from the Agence Nationale de la Recherche (ANR) and the European Funds for the Regional Development. Authors thank B. Wathelet from the Université des Sciences Agronomiques de Gembloux for MALDI-MS analysis and also A.S. Drucbert from the Faculté de Médecine H. Warembourg and L. Bonneau from the Université des Sciences et Technologies de Lille for technical assistance. 


\section{References}

Anderlei, T., Zang, W., Papaspyrou, M., Büchs, J. (2004) Online respiration activity measurement (OTR, CTR, RQ) in shake flasks. Biochem. Eng. J. 17, 187-194.

Bonmatin, J.M., Laprevote, O., Peypoux, F. (2003) Diversity among microbial cyclic lipopeptides: Iturins and surfactins. Activity-structure relationships to design new bioactive agents. Combinat. Chem. High Troughpout Screen. 6, 541-556.

Çalik, P., Çalik, G., Özdamar, T.H. (2000) Oxygen-transfer strategy and its regulation effects in serine alkaline protease production by Bacillus licheniformis. Biotechnol. Bioeng. 69(3), 301-311.

Clark, J.B., Munnecke, D.M., Jenneman, G.E. (1981) In situ microbial enhancement of oil recovery. Devel. Ind. Microbiol. 22, 695-701.

Desai, J.D. and Banat, I.M. (1997) Microbial production of surfactants and their commercial potential. Microbiol. Mol. Biol. R. 61, 47-64.

Duitman, E.H., Hamoen, L.W., Rembold, M.,, Venema, G., Seitz, H., Saenger, W., Bernhard, F., Reinhardt, R., Schmidt, M., Ullrich, C., Stein, T., Leenders, F. and Vater, J. (1999) The mycosubtilin synthetase of Bacillus subtilis ATCC6633: A multifunctional hybrid between a peptide synthetase, an amino transferase, and a fatty acid synthase. PNAS. 96(23), 1329413299.

Duitman, E.H., Dobek, W., Boven, L.G., Venema, G., Kuipers O.P. and Hamoen L.W. (2007) Novel methods for genetic transformation of natural Bacillus subtilis isolates used to study the regulation of the mycosubtilin and surfactin synthetases. Appl. Environ. Microbiol. 73(11), 3490-3496. 
Grünewald, J. and Marahiel, M.A. (2006) Chemoenzymatic and template-directed synthesis of bioactive macrocyclic peptides. Microbiol. Mol. Biol. R. 70(1), 121-146.

Guez J.S., Chenikher S., Cassar J.Ph., Jacques P. (2007) ${ }^{\mathrm{a}}$ Setting up and modelling of overflowing fed-batch cultures of Bacillus subtilis for the production and continuous removal of lipopeptides. J. Biotechnol. 131, 67-75.

Guez, J.S. $(2007)^{\mathrm{b}}$ Etude de la productivité et de la sélectivité de la biosynthèse de mycosubtiline, un antibiotique surfactant de Bacillus subtilis. Dissertation. Université des Sciences et Technologies de Lille.

Hansen D.B., Bumpus S.B., Aron Z.D., Kelleher N.L., Walsh C.T. (2007) The loading module of mycosubtilin: an adenylation domain with fatty acid selectivity. J. Am. Chem. Soc. 129, 6366-6367.

Hbid, C., Jacques, P., Razafindralambo, H., Mpoyo, M.K., Meurice, E., Paquot, M., Thonart, P. (1996) Influence of the production of two lipopeptides, Iturin A and Surfactin S1, on oxygen transfer during Bacillus subtilis fermentation. Appl. Biochem. Microbiol. 57-58, 571579.

Jacques, P., Hbid, C., Destain, J., Razafindralambo, H., Paquot, M., De Pauw, E., Thonart, P. (1999) Optimization of biosurfactant lipopeptide production from Bacillus subtilis S499 by Plackett-Burman design. Appl. Biochem. Biotech. 77, 223-233.

Leclère, V., Béchet, M., Adam, A., Guez, J.S., Wathelet, B., Ongena, M., Thonart, P., Gancel, F., Chollet-Imbert, M., Jacques, P. (2005) Characterization of a constitutive mycosubtilin 
overproducing Bacillus subtilis strain and its antagonistic activity. Appl. Environ. Microbiol. 71(8), 4577-4584.

Lee, B.S. and Kim, E.K. (2004) Lipopeptide production from Bacillus sp. GB16 using a novel oxygenation method. Enz. Microb. Tech. 35, 639-647.

Maget-Dana, R. and Peypoux, F. (1994) Iturins, a special class of pore-forming lipopeptides: Biological and physicochemical properties. Toxicology. 87(1-3), 151-174

Ohno, A., Ano, T., Shoda, M. (1993) Effect of temperature change and aeration on the production of the antifungal peptide antibiotic iturin by Bacillus subtilis NB22 in liquid cultivation. J. Ferment. Bioeng. 75(6), 463-465.

Schneider, J., Taraz, K., Budzikiewicz, H., Deleu, M., Thonart, P., Jacques, P. (1999) The structure of two fengycins from Bacillus subtilis S499. Z. Naturforsch. C 54(11), 859-865.

Sen, R. and Swaminathan, T. (1997) Application of response-surface methodology to evaluate the optimum environmental conditions for the enhanced production of surfactin. Appl. Microbiol. Biotechnol. 47, 358-363. 
Figure 1: Evolution of oxygen transfer rate (OTR), expressed in $\mathrm{mol} \mathrm{O}_{2} \cdot \mathrm{l}^{-1} \cdot \mathrm{h}^{-1}$, during growth of B. subtilis ATCC6633 in RAMOS flasks with a filling volume (FV) of $10 \mathrm{ml}(-\downarrow-), 25 \mathrm{ml}(-$ --), $42 \mathrm{ml}\left(-\mathbf{\Delta}^{-}\right)$and $60 \mathrm{ml}(-\bullet-)$. Displayed data corresponds to four experiments led simultaneously. The experiment with a FV of $42 \mathrm{ml}$ is representative of a triplicate set.

Figure 2: Evolution of the mycosubtilin (A and $\mathrm{B}$ ) and surfactin (C and $\mathrm{D})$ production expressed in mg. $1^{-1}$ during growth-limited cultures of B. subtilis ATCC6633 and BBG100 in

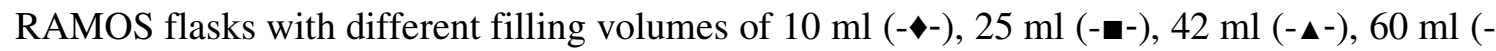
--). For each FV condition, displayed kinetics data corresponds to one RAMOS and three non-monitored flasks experiments led simultaneously.

Figure 3: Effect of different oxygen-limited growths obtained in flasks with different filling volume ratios (FVR) of $0.05,0.1,0.2$ and 0.4 on the expression of the fenF gene of B. subtilis ATCC6633. The culture medium was the modified Landy medium buffered with MOPS 100 $\mathrm{mM}$ at $\mathrm{pH}$ 7.0. Comparative RT-PCR gels for fenF and $r p l L$ and the corresponding rplL normalised MTM ratios for fenF are presented for doubling times of 2 and 4 ( $\square$ ). Experiments were realised in duplicates ( $\square$ and $\mathbf{\square}$ ).

Figure 4: Evolution of the mycosubtilin productivity, expressed in $\mathrm{mg} \cdot \mathrm{g}(\mathrm{DW})^{-1} \cdot \mathrm{h}^{-1}$, and mycosubtilin homologues C-16 ( $\square$ ) and C-17 ( $\square$ ) patterns for cultures of B. subtilis ATCC6633 led at FVR of 0.05, 0.1, 0.2 and 0.4. Data originated from a triplicate set.

Table 1: Measured values of the $\mathrm{pH}$, optical density at $600 \mathrm{~nm}$, glucose, glutamic acid and mycosubtilin concentrations after $48 \mathrm{~h}$ of culture at $30^{\circ} \mathrm{C}$ and shaking at $175 \mathrm{rpm}$ in the 
RAMOS. Displayed data corresponds to 4 experiments led simultaneously at different filling volumes of 10, 25, 42 and $60 \mathrm{ml}$.

Appendix 1: MALDI-MS spectrum of the partially purified C-16 and C-17 mycosubtilin homologues. Identification of the $\left[\mathrm{M}+\mathrm{K}^{+}\right]$ions of $\mathrm{C}-16$ and $\mathrm{C}-17$ mycosubtilin homologues was done according to their calculated $\mathrm{m} / \mathrm{z}$ values, 1109.539 and 1123.554 uma. 


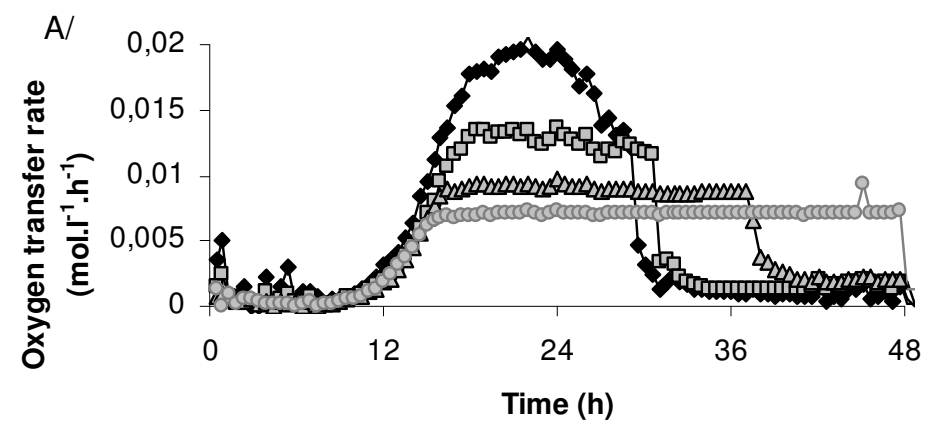

Figure 1 

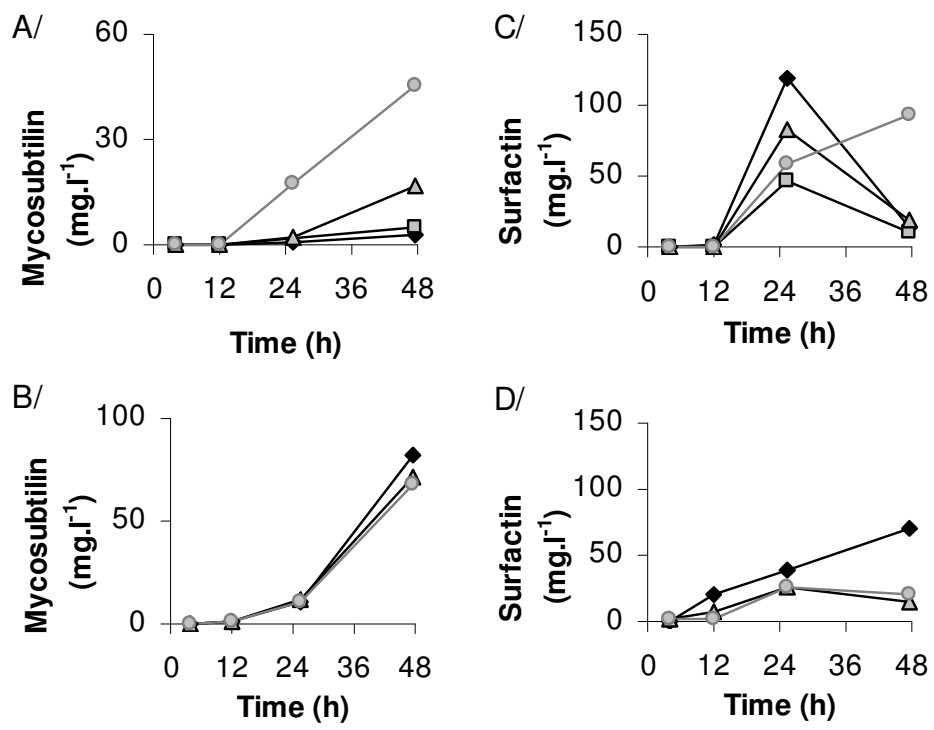

Figure 2 


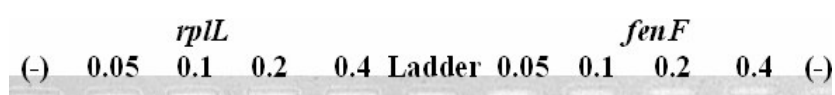

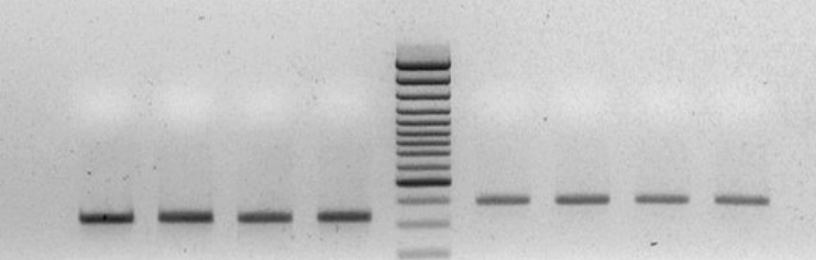

Doubling times $(n=2)$

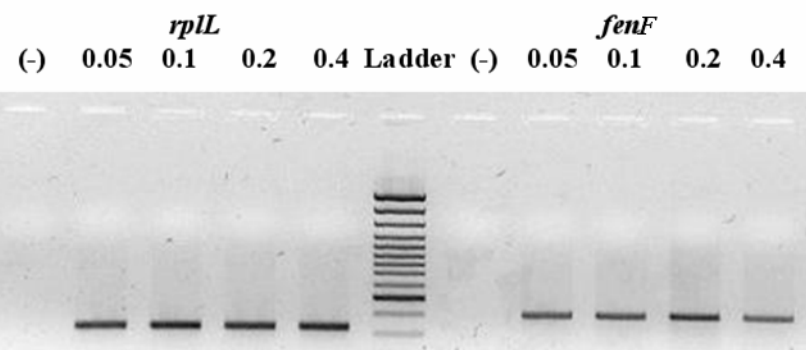

Doubling times $(n=4)$
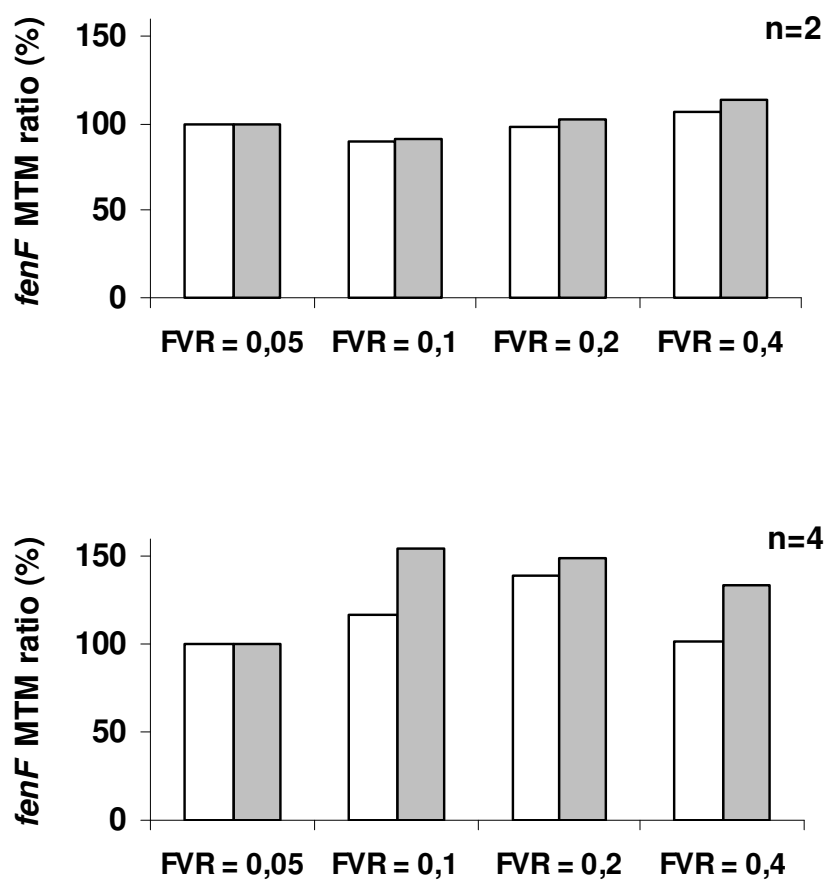

Figure 3 

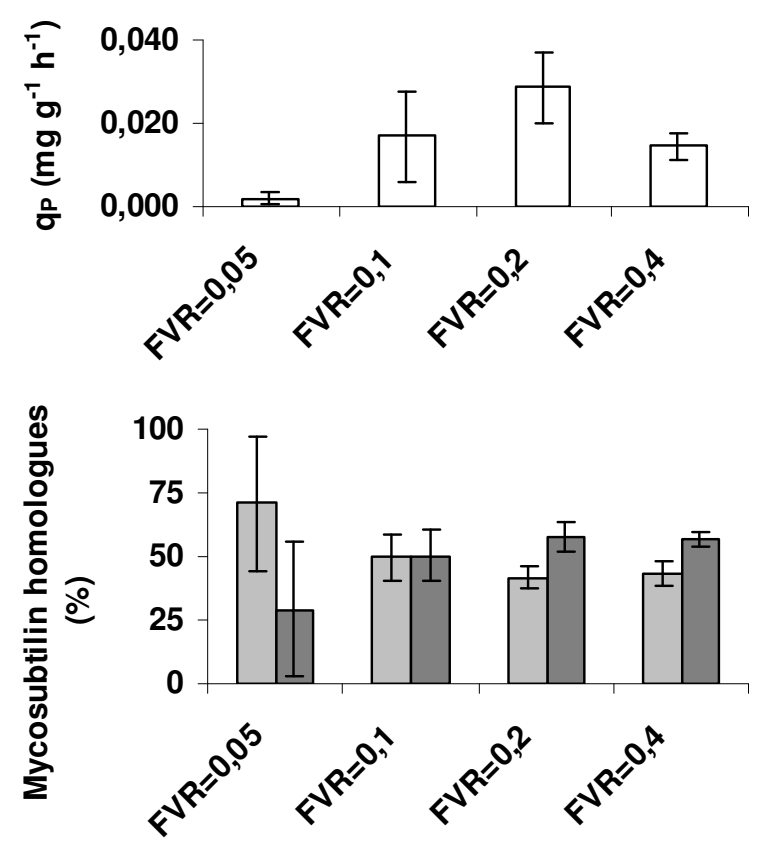

Figure 4 

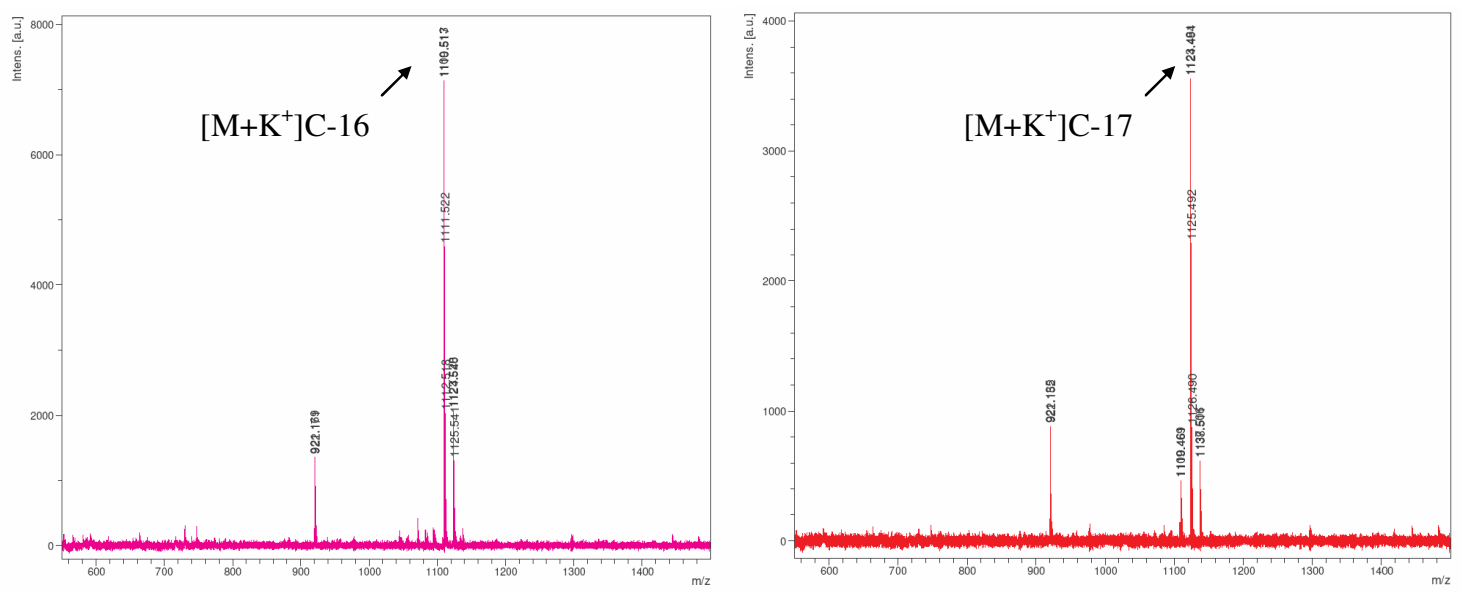

Appendix 1 
Table 1

\begin{tabular}{|c|c|c|c|c|c|c|c|}
\hline Strain & $\begin{array}{l}\text { Filling Volume } \\
\qquad(\mathrm{ml})\end{array}$ & $\mathrm{pH}$ & OD & $\begin{array}{c}\text { Glucose } \\
\left(\text { g. } \text { I }^{-1}\right)\end{array}$ & $\begin{array}{c}\text { Glutamic acid } \\
\qquad\left(\text { g. } l^{-1}\right)\end{array}$ & $\begin{array}{c}\text { mycosubtilin } \\
\left(\mathrm{mg}^{-1} \mathrm{I}^{-1}\right)\end{array}$ & $\begin{array}{c}\mathrm{q}_{\mathrm{P}} \\
\left(\mathrm{mg} \cdot \mathrm{g}(\mathrm{DW})^{-1} \mathrm{~h}^{-1}\right)\end{array}$ \\
\hline \multirow{4}{*}{6633} & 10 & 6.02 & 15.2 & 0 & 0.017 & 2.8 & 0.001 \\
\hline & 25 & 6.06 & 14.9 & 0 & 0.021 & 4.7 & 0.002 \\
\hline & 42 & 6.08 & 18.1 & 0 & 0.034 & 16.9 & 0.006 \\
\hline & 60 & 6.07 & 11.2 & 0.45 & 0.056 & 45.4 & 0.025 \\
\hline \multirow{3}{*}{ BBG100 } & 10 & 5.96 & 15.7 & 0.07 & 0.016 & 82.2 & 0.033 \\
\hline & 42 & 5.88 & 12.2 & 2.8 & 0.039 & 72 & 0.037 \\
\hline & 60 & 6.10 & 12.3 & 2.4 & 0.028 & 67.9 & 0.035 \\
\hline
\end{tabular}

